\title{
5-HT7 receptor signaling: improved therapeutic strategy in gut disorders
}

\author{
Janice J. Kim and Waliul I. Khan * \\ Department of Pathology and Molecular Medicine, Farncombe Family Digestive Health Research Institute, McMaster University, Hamilton, ON, Canada
}

\section{Edited by:}

Walter Adriani, Istituto Superiore di

Sanitá, Italy

\section{Reviewed by:}

Yueqiang Xue, The University of

Tennessee Health Science

Center, USA

Maria Cecilia Giron, University of

Padova, Italy

Evgeni Ponimaskin, Hannover

Medical School, Germany

Kris Chadee, University of Calgary,

Canada

${ }^{*}$ Correspondence:

Waliul I. Khan, Department of

Pathology and Molecular Medicine,

Farncombe Family Digestive Health

Research Institute, McMaster

University, 1280 Main Street West,

Health Sciences Centre Room 3N7,

Hamilton, ON L8S4K1, Canada

e-mail: khanwal@mcmaster.ca
Serotonin (5-hydroxytryptamine; 5-HT) is most commonly known for its role as a neurotransmitter in the central nervous system (CNS). However, the majority of the body's $5-\mathrm{HT}$ is produced in the gut by enterochromaffin (EC) cells. Alterations in 5-HT signaling have been associated with various gut disorders including inflammatory bowel disease (IBD), irritable bowel syndrome (IBS) and enteric infections. Recently, our studies have identified a key role for $5-\mathrm{HT}$ in the pathogenesis of experimental colitis. $5-\mathrm{HT}_{7}$ receptors are expressed in the gut and very recently, we have shown evidence of $5-\mathrm{HT}_{7}$ receptor expression on intestinal immune cells and demonstrated a key role for $5-\mathrm{HT}_{7}$ receptors in generation of experimental colitis. This review summarizes the key findings of these studies and provides a comprehensive overview of our current knowledge of the $5-\mathrm{HT}_{7}$ receptor in terms of its pathophysiological relevance and therapeutic potential in intestinal inflammatory conditions, such as IBD.

Keywords: inflammatory bowel disease, serotonin receptor type 7

\section{INTRODUCTION}

The gastrointestinal (GI) tract contains an extensive system of endocrine cells that are interspersed amongst gut epithelial cells (Rehfeld, 1998). There are several subpopulations of endocrine cells, which release various biologically active compounds such as gastrin, secretin, cholecystokinin, chromogranin, and serotonin (5-hydroxytryptamine; 5-HT; Sharkey and Mawe, 2002). Enterochromaffin (EC) cells are the best characterized subset of enteric endocrine cells and constitute the largest endocrine cell population in the gut (Ham, 2002; Sharkey and Mawe, 2002; Ku et al., 2006; Gunawardene et al., 2011). EC cells arise from multipotent stem cells located near the base of the crypts of Lieberkühn and are the body's main source of 5-HT (Sharkey and Mawe, 2002; Gunawardene et al., 2011). Alterations in EC cells and 5HT signaling has been shown to be associated in a number of GI disorders including inflammatory bowel disease (IBD), irritable bowel syndrome (IBS), and enteric infections, emphasizing the importance of 5-HT signaling in intestinal homeostasis.

5-HT mediates many GI functions, including secretion and peristalsis, by activating of a diverse range of 5-HT receptors (Mawe and Hoffman, 2013). To date, seven types of 5-HT receptors have been identified and amongst these, five are expressed within the GI tract. This paper reviews information on the most recently identified class of 5-HT receptors, $5-\mathrm{HT}_{7}$, and its role in the GI tract with a focus on its implications in understanding the pathophysiology of intestinal disorders.

\section{5-HT IN THE GI TRACT}

5-HT is a highly conserved biogenic amine that is found in separate peripheral and central tissue pools that are distinctly regulated by two different rate-limiting enzymes, tryptophan hydroxylase (TpH) 1 and 2, respectively (Walther and Bader, 2003; Walther et al., 2003). TpH1 found in EC cells catalyzes the majority of 5-HT production in the body (roughly $\sim 90 \%$ ). TpH1 converts dietary L-tryptophan to 5-hydroxytryptophan (5-HTP), which is then converted to 5-HT by L-amino acid decarboxylase (Bertrand and Bertrand, 2010). Once synthesized, 5-HT is packaged into granules by the vesicular monoamine transporter 1 (VMAT1; Rindi et al., 2004; Schäfermeyer et al., 2004) and released mainly from granules stored near the basal border of the EC cell, though some studies have identified granules near the apical membrane (Nilsson et al., 1987). EC cells release 5$\mathrm{HT}$ in response to various mechanical and chemical stimuli, including bacterial toxins, in a calcium-dependent manner (Racké et al., 1996; Mössner and Lesch, 1998). Once released, 5-HT participates in various gut functions, including secretion and peristalsis, by activation of a diverse range of 5-HT receptors located in the lamina propria (LP; Mawe and Hoffman, 2013). The actions of 5-HT are terminated by uptake by the serotonin reuptake transporter (SERT) into adjacent epithelial cells (Martel et al., 2003) and degradation by monoamine oxidase A $\left(\mathrm{MAO}_{\mathrm{A}}\right)$. SERT is also found in platelets and enteric neurons (Bertrand and Bertrand, 2010), and is the target for important 
therapeutic drugs such as fluoxetine and citalopram, members of the family of serotonin-selective reuptake inhibitors (SSRIs). SERT mediated reuptake of 5-HT can be partially replaced by the dopamine transporter (DAT) and organic cation transporter (OCT), albeit at a lower affinity than SERT (Chen et al., 2001).

\section{5-HT SIGNALING IN INTESTINAL INFLAMMATION}

IBDs, Crohn's disease (CD) and ulcerative colitis (UC), are serious chronic inflammatory conditions of the human bowel currently affecting approximately 1-2 million people in the US and Canada (Loftus, 2004). Although the pathogenesis of IBD remains unknown, it is a multifactorial disease that involves both genetic and environmental components. As such, IBD is considered to be an inappropriate immune response that occurs in genetically susceptible individuals as a result of a complex interaction between environmental factors, microbial factors, and the intestinal immune system (Bouma and Strober, 2003; Bernstein and Shanahan, 2008; Koloski et al., 2008; Arnett and Viney, 2010). During the past five decades, the frequency of IBD has increased rapidly in highly industrialized Western nations with Canada having one of the highest incidence rates of both UC and CD worldwide (Fedorak et al., 2010).

Alterations in 5-HT signaling have been observed in IBD (Ahonen et al., 1976; Belai et al., 1997; El-Salhy et al., 1997; Magro et al., 2002; Coates et al., 2004) and changes to EC cell numbers and 5-HT content have been associated with both UC and CD (Bishop et al., 1987; Belai et al., 1997; El-Salhy et al., 1997). Changes in 5-HT signaling have also been shown in various experimental models of intestinal inflammation, including trinitrobenzene sulphonic acid (TNBS), di-nitrobenzene sulphonic acid (DNBS), and dextran sulfate sodium (DSS; Oshima et al., 1999; Linden et al., 2005; Khan et al., 2006). In all of these models, EC cell numbers and 5-HT levels are increased. In addition, infection with either Trichuris muris or Citrobacter rodentium, leads to an increase in EC cells numbers and/or 5-HT release, further supporting a role for 5-HT in inflammatory states (O'Hara et al., 2006; Motomura et al., 2008).

5-HT itself also plays a key role in the generation of intestinal inflammation. Previously, we have shown that there is significant reduction in intestinal inflammation post- DSS and DNBS-induced colitis when intestinal 5-HT levels are reduced by genetic deletion of the rate-limiting $\mathrm{TpH} 1$ enzyme or by using parachlorophenylalanine (pCPA), while replenishing 5-HT levels intensifies colitis severity (Ghia et al., 2009). In turn, studies have also shown that chemical-induced colitis or spontaneous colitis associated with an IL-10 deficiency is increased in severity when coupled with the 5-HT enhancing effects of a knockout of SERT (Bischoff et al., 2009; Haub et al., 2010). Prior approaches aimed at blocking 5-HT synthesis by a pharmacological agent through inhibition of $\mathrm{TpH}$, as with $\mathrm{pCPA}$, have been impeded by adverse effects to brain 5-HT synthesis leading to alterations in central nervous system (CNS)-mediated functions (Ruhé et al., 2007). Recently, we have also shown that blocking 5-HT synthesis using an orally-delivered small molecule $\mathrm{TpH}$ inhibitor, telotristat etiprate (LX1032/LX1606), effectively reduces peripheral 5-HT synthesis and both chemical- and infection-induced intestinal inflammation (Kim et al., 2013b). This compound is unable to cross the blood-brain barrier (Savelieva et al., 2008) and does not appear to affect enteric neuronal TpH2 (Margolis et al., 2013). Oral administration of LX1606 significantly depletes intestinal 5-HT levels but does not affect brain 5-HT levels. Margolis et al. (2013) also evaluated the effect of LX1606 on neuronal 5 -HT stores using immunocytochemical techniques and found that LX1606 did not affect the proportion of myenteric 5-HTimmunoreactive neurons or the area of myenteric plexus occupied by 5 -HT-immunoreactive nerve fibers. This suggests that while LX1606 significantly depletes 5-HT stores from EC cells, entire neuronal 5-HT stores are maintained and therefore, LX1606 and similarly related peripheral $\mathrm{TpH}$ inhibitors appear to fail to enter the myenteric plexus and/or inhibit enteric neuronal TpH2.

The precise mechanisms by which 5-HT exerts its proinflammatory actions remains to be determined. To elucidate this mechanism, we assessed the role of 5-HT in dendritic cell (DC) function in relation to gut inflammation. EC cells are located in very close proximity to or in contact with immune cells such as DCs (Yang and Lackner, 2004) and studies from our lab and others have shown an important role for 5-HT in immune regulation and in turn, immune-mediated alteration of EC cells/5-HT signaling (Wang et al., 2007; Li et al., 2011; Shajib et al., 2013). DCs are professional antigen-presenting cells with the ability to initiate adaptive immune responses. Intestinal DCs reside in the LP as such, are able to continuously sample luminal contents. DCs play a critical role in orchestrating immune responses and have been shown to be important in the generation of intestinal inflammation (Lipscomb and Masten, 2002; Berndt et al., 2007). DCs isolated from TpH1 deficient mice following DSS administration release significantly less IL12 compared with DCs isolated from wild-type mice (Li et al., 2011). Interestingly, when DCs isolated from TpH1 deficient mice are cultured in the presence of 5-HT, this restores IL-12 levels to those comparable to DCs from wild-type mice suggesting a role of 5-HT mediated activation of DCs. Furthermore, when 5-HT stimulated DCs are transferred back into TpH1 deficient mice, there is significant increase in colitis severity and this is associated with higher myeloperoxidase (MPO) activity and proinflammatory cytokine (IL-1 $\beta$ and IL-6) levels. This suggests that 5 -HT mediated modulation of DC function is important in the pathogenesis of colitis though research targeting 5-HT signaling is needed to translate these observations for clinical utilization and to design a therapeutic strategy for colitis.

\section{INTESTINAL INFLAMMATION AND THE GUT-BRAIN-AXIS}

The gut-brain-axis is a bi-directional neuro-humoral communication system that links gut and brain function in health and disease, and contributes to GI functions, including motility, secretion, visceral sensations, and mucosal immunity (Collins and Bercik, 2009; El Aidy et al., 2012; Forsythe and Kunze, 2013). The importance of this axis is demonstrated by its role in IBS and is reflected in the high prevalence of psychiatric morbidity in IBS (Whitehead et al., 2002). There is also growing evidence that the gut-brain-axis plays a role in IBD (Graff et al., 2009; Bonaz and Bernstein, 2013). IBD results in high morbidity and mortality and severely compromises quality of life and life expectancy. In 
recent years, there has been increasing recognition that depression can worsen the course of IBD (Mardini et al., 2004; Mittermaier et al., 2004; Persoons et al., 2005) and it has been shown that persons with IBD have higher rates of depression (in addition to panic, generalized anxiety, obsessive-compulsive disorders) compared with control populations (Walker et al., 2008). The mechanisms underlying this relationship in terms of cause-andeffect are currently unclear. In a study by Walker et al. (2008), it was reported that patients with IBD have a higher 12-month and also lifetime prevalence of major depression whereby approximately half experienced a first episode of depression more than 2 years before the onset of IBD. Depression may also negatively affect the course and outcome of disease. A prospective study by Mittermaier et al. (2004) found that in patients with IBD, those with significant depressive symptoms (at baseline) had relapses that occurred sooner and more frequently. In patients with CD, major depressive disorder has been reported as a risk factor for failure to achieve remission with infliximab treatment and an earlier need for retreatment (Persoons et al., 2005). In addition, studies have found that patients with active disease report higher levels of depression and anxiety while those with quiescent disease report lower levels (Porcelli et al., 1996; Levenstein, 2002; Larsson et al., 2008). As such, it has been proposed that treatments that improve mood may be useful in improving symptoms and disease activity in IBD. Antidepressants such as SSRIs are generally well tolerated and are successful in relieving psychological symptoms in about $30-40 \%$ of patients (Trivedi et al., 2006; Krishnan and Nestler, 2008). Recently, it was reported that antidepressants used to treat concomitant mood disorders in patients with IBD improves relapse rates and use of corticosteroids when compared with matched controls. Whether this occurred through a direct effect of the drug on the GI tract, or indirectly via improvement in mood and stress response was not investigated (Goodhand et al., 2012). Uncontrolled case report studies have also reported improvements not only in depression but also in IBD symptom scores (Mikocka-Walus et al., 2006). In contrast, data from a single open-label study of SSRI in IBD patients with depression reported improvements in depression but not in IBD activity (Walker et al., 1996). Moving forward, there is a need for randomized controlled trials to assess the effects of antidepressants such as SSRIs on disease activity in patients with IBD.

Studies using animal models have provided insight into mechanisms involved in the gut-brain-axis during GI inflammation and infection. Lyte et al. (1998) showed that mice treated orally with Campylobacter jejuni had increased anxiety-like behavior compared to saline-treated control mice. This was without any increase in inflammatory mediators and likely due to activation of vagal ascending pathways. In experimental models that result in increased GI inflammation, there are increases in anxiety-like behavior. In animal models of colitis, mice treated with DSS show increased anxiety-like behavior (Bercik et al., 2011). In addition, mice infected with Trichuris muris demonstrated intestinal inflammation that was associated with increased anxiety-like behavior when tested using the light/dark test and step-down test methods (Bercik et al., 2010). This was accompanied by decreased brain derived neurotropic factor (BDNF) expression in the hippocampus, and elevated levels of TNF- $\alpha$, INF- $\gamma$, and kynurenine.
Abnormal behavior (but not BDNF levels) was normalized by treatment with immunomodulators, etanercept and budesonide. Interestingly, both behavior and BDNF levels normalized following administration with probiotic Bifidobacterium longum suggesting a role for gut microbiota in modulating behavior. The role of the microbiota on the gut-brain-axis, however, is beyond the scope of this review, and has been extensively reviewed elsewhere (Cryan and O'Mahony, 2011; Collins et al., 2012). What is clear from the growing body of literature, is that the gut microbiome plays a critical role in regulating normal function of the gutbrain axis. Recently, there is a growing body of evidence looking at the role of 5-HT and the gut microbiome suggesting that 5HT may be critically involved at every level of the brain-gutmicrobiome axis (as reviewed by O'Mahony et al., 2014). With a better understanding of the interaction between this axis and the 5-HT system, this could aid in the design and development of novel therapeutic strategies for intestinal disorders that target 5-HT signaling with far-reaching effects beyond the gut. This may be particularly relevant in GI inflammatory disorders such as IBS and IBD with reported psychiatric comorbidities.

\section{5-HT 7 RECEPTORS IN THE GUT}

The discovery of 5-HT in the late 1940s was shortly followed by evidence for 5-HT receptor heterogeneity. To date, seven distinct families of 5-HT receptors have been identified, with some families consisting of various subpopulations (Hoyer et al., 2002). Five of the seven known families $\left(5-\mathrm{HT}_{1}, 5-\mathrm{HT}_{2}, 5-\mathrm{HT}_{3}\right.$, $5-\mathrm{HT}_{4}$, and $5-\mathrm{HT}_{7}$ receptors) are expressed in the gut (Hoyer et al., 2002), with the $5-\mathrm{HT}_{3}$ and $5-\mathrm{HT}_{4}$ receptor subtypes being the most extensively studied. $5-\mathrm{HT}_{3}$ and $5-\mathrm{HT}_{4}$ receptors have been targeted for the treatment of diarrhea and constipation, respectively (Mawe and Hoffman, 2013). The $5-\mathrm{HT}_{7}$ receptor is the most recently discovered member of the 5-HT receptor family and has since been cloned in rat (Lovenberg et al., 1993; Meyerhof et al., 1993; Ruat et al., 1993; Shen et al., 1993), mouse (Plassat et al., 1993), guinea pig (Tsou et al., 1994), porcine (Bhalla et al., 2002), and human (Bard et al., 1993).

The $5-\mathrm{HT}_{7}$ receptor is expressed in both the CNS and in peripheral tissues. In the CNS, pharmacological and animal studies using $5-\mathrm{HT}_{7}$ receptor deficient mice have established roles for the $5-\mathrm{HT}_{7}$ receptor in control of circadian rhythms and thermoregulation (Lovenberg et al., 1993; Tsou et al., 1994; Hedlund et al., 2003), learning and memory (Roberts and Hedlund, 2012), and mood disorders including depression (Hedlund, 2009; MnieFilali et al., 2009). In the periphery, 5- $\mathrm{HT}_{7}$ receptors have been found to be expressed in the colon, ileum, and stomach with low expression in the spleen, liver, and kidney (Bard et al., 1993). $5-\mathrm{HT}_{7}$ receptors have also been reported to be expressed on human enterocyte-like cell line, Caco-2 cells, and was found to modulate SERT activity (Iceta et al., 2009). Blood-derived DCs also express the $5-\mathrm{HT}_{7}$ receptor (Shen et al., 1993; Vanhoenacker et al., 2000; Idzko et al., 2004).

Specifically within the gut, $5-\mathrm{HT}_{7}$ receptors are expressed on smooth muscle cells, enteric neurons, and within the solitary intestinal lymphoid tissue, small-sized intestinal lymphoid structures scattered through the small intestine (Tonini et al., 2005; Guseva et al., 2014). Recently, we have shown that the $5-\mathrm{HT}_{7}$ 
receptor is also expressed on intestinal LP DCs (Kim et al., 2013a; Figure 1). DCs represent a heterogeneous population with functional diversity with different DC subsets having distinct sets of cell surface antigens. Although CD11c is the classical integrin marker used to distinguish DCs from macrophages (whereby $\mathrm{CD}_{11} \mathrm{~b}^{+} \mathrm{CD}_{11 \mathrm{c}^{-}}$and CD11b+/-CD11 $\mathrm{c}^{\text {high }}$ are classified as macrophages and DCs, respectively), this becomes more difficult when distinguishing between LP macrophage and DC populations, as LP macrophages express both CD11b and CD11c markers (Mowat and Bain, 2011). Therefore, it is important to use differential expression of integrin CD103 ( $\alpha \mathrm{E}$ integrin) to reliably distinguish between these two populations. We found that isolated intestinal $\mathrm{CD}_{103}{ }^{+} \mathrm{CD}_{11 \mathrm{c}^{+}}$cells were positive for $5-\mathrm{HT}_{7}$ receptor expression whereas no significant amount was detected on $\mathrm{CD}_{103}{ }^{-} \mathrm{CD}_{11 \mathrm{c}^{+}}$cells. Adding to this finding, Guseva et al. (2014) recently reported that CD11c+ CD86+ cells colocalize with $5-\mathrm{HT}_{7}$ receptor staining in colon samples collected from both inflamed and non-inflamed areas of patients with CD. CD86 is a co-stimulatory molecule found on mature DCs. These findings suggest that $5-\mathrm{HT}_{7}$ receptor expressed by DCs may play a role in modulating intestinal inflammation in this patient population.
Under physiological conditions, there is evidence that $5-\mathrm{HT}_{7}$ receptors play a role in motility by mediating smooth muscle relaxation in colon (Prins et al., 1999; Tonini et al., 2005) and ileum smooth muscle (Carter et al., 1995). In addition, they are believed to have a role in initiating murine colonic migrating motor complexes (Dickson et al., 2010). 5- $\mathrm{HT}_{7}$ receptors may also have a role in inhibition of peristalsis by 5 -HT (Tuladhar et al., 2003; Table 1).

\section{5-HT 7 RECEPTOR SIGNALING IN INTESTINAL DISORDERS IRRITABLE BOWEL SYNDROME}

A number of studies have reported altered 5-HT signaling activity in intestinal disorders. Therapeutic drugs to target selective modulation of 5-HT activity - including SSRIs, 5- $\mathrm{HT}_{3}$ and $5-\mathrm{HT}_{4}$ antagonists and agonists, respectively-have been used in the treatment of functional GI disorders such as IBS (Gershon and Tack, 2007; Beattie and Smith, 2008). Some of these drugs, however, have been associated with unwanted side effects (Ladabaum, 2003; Cole et al., 2004) and thus, prompts the need for more studies on 5-HT and its receptors in GI pathology and pathophysiology. IBS is a functional bowel disorder in which abdominal

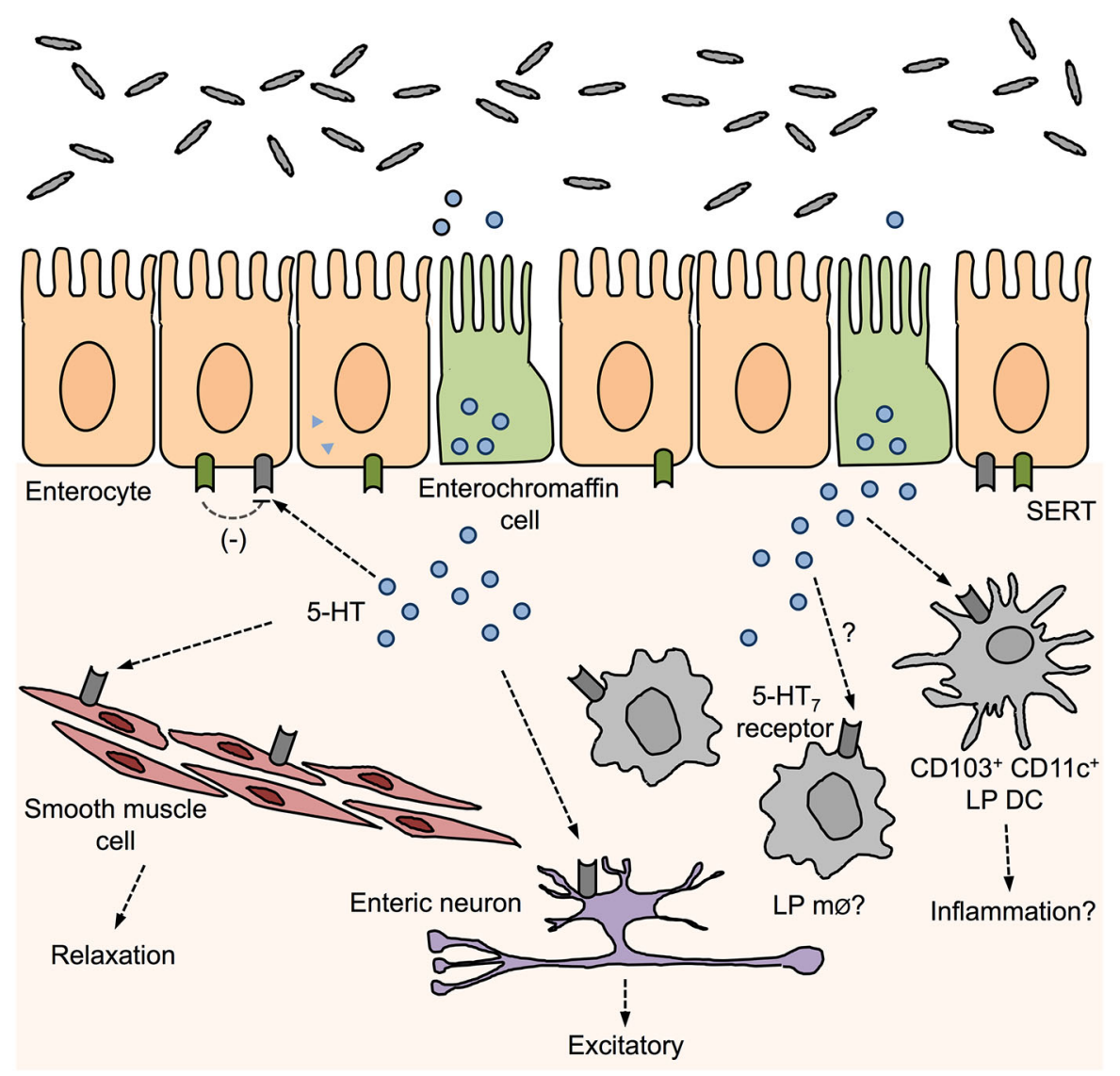

FIGURE 1 | Distribution of $5-\mathrm{HT}_{7}$ receptors in the gut and proposed roles in gut function. 5-hydroxytryptamine (5-HT) released from enterochromaffin cells can act on surrounding $5-\mathrm{HT}_{7}$ receptors that are expressed by smooth muscle cells, enteric neurons, enterocytes, and immune cells. Activation of $5-\mathrm{HT}_{7}$ receptors can influence muscle tone, enteric neuron excitation, and have been proposed to inhibit SERT activity and promote inflammation by activation of LP dendritic cells (DCS) 
Table 1 | Effects of $5-\mathrm{HT}_{7}$ receptor activation or inactivation on gut function.

\begin{tabular}{llll}
\hline Species/Region & $\mathbf{5 - H T}$ activation/inhibition & Effect & Reference \\
\hline Guinea pig ileum & Antagonist SB-269970 & Restores 5-HT inhibited peristalsis & Tuladhar et al. (2003) \\
& Antagonist SB-269970 & Inhibits 5-HT inhibited peristalsis (via enteric neurons) & Tonini et al. (2005) \\
& Agonist 8-OH-DPAT & Elicits relaxation & Carter et al. (1995) \\
Guinea pig mesentary & Antagonist SB-269970 & Inhibits 5-HT inhibited constriction & Chan and von der Weid (2003) \\
Mouse colon & Antagonist SB-269970 & Inhibits spontaneous & Dickson et al. (2010) \\
Canine stomach & Antagonist SB-258719 & colonic migrating motor complexes & Janssen et al. (2002) \\
Human colon & Antagonist SB-269970 & Inhibits 5-Carboxamidotryptamine (5-CT) & Irving et al. (2007) \\
& Antagonist SB-269970 & Inhibits 5-HT induced relaxation of & Prins et al. (1999)
\end{tabular}

pain and discomfort is associated with altered bowel habits. 5HT plays a key role in regulating motor functions of the GI tract and studies have suggested that $5-\mathrm{HT}_{7}$ receptors mediate smooth muscle relaxation, adding to the rationale for investigating $5-\mathrm{HT}_{7}$ receptor ligands in IBS. In addition, they play a role in regulation of nociceptive pathways (Meuser et al., 2002) and thus, may be involved in the pathological mechanisms underlying visceral paresthesia seen in IBS. Zou et al. (2007) investigated the role of $5-\mathrm{HT}_{7}$ receptors in the pathogenesis of IBS in a rodent model and found that $5-\mathrm{HT}_{7}$ receptor expression was increased in the hippocampus, hypothalamus, and intestine (ileum and colon) of IBS groups as compared to controls and this was associated with higher cAMP levels at these sites. In addition, there is a high prevalence of comorbid depression and anxiety disorders in IBS patients (Andresen and Camilleri, 2006). As 5- $\mathrm{HT}_{7}$ receptors have been linked with depression (although its role in anxiety is currently inconclusive) (as reviewed by Hedlund, 2009), it may be an attractive potential therapeutic target for IBS with effects extending beyond the gut.

\section{INFLAMMATORY BOWEL DISEASE}

The role of $5-\mathrm{HT}_{7}$ receptors in IBD is far less studied. Very recently, however, Guseva et al. (2014) has reported that $5-\mathrm{HT}_{7}$ receptor expression is increased in inflamed sections of $\mathrm{CD}$ patients. In addition, using experimental models of colitis, we have previously reported that $5-\mathrm{HT}_{7}$ receptor levels are increased in the colon of mice post- DSS-induced colitis (Kim et al., 2013a). In addition, Guseva et al. (2014) also found an up-regulation in $5-\mathrm{HT}_{7}$ receptor expression in cecum and rectum in DSS-treated animals compared with controls. Ours and other studies have also shown that the $5-\mathrm{HT}_{7}$ receptor is expressed on DCs (Idzko et al., 2004; Kim et al., 2013a; Guseva et al., 2014). EC cells, the major producer of 5-HT in the gut, are located in close proximity to these cells and thus, it is likely that there is interplay between these two systems. We proposed that inhibiting 5-HT signaling by blocking $5-\mathrm{HT}_{7}$ receptor function would lead to attenuation of immune cell activation and subsequent inflammation. Indeed, we found that blocking 5-HT signaling by using a selective $5-\mathrm{HT}_{7}$ receptor antagonist (SB-269970) or by genetic deletion of this receptor alleviated intestinal inflammation in two separate chemical models of colitis (DSS and DNBS) (Kim et al., 2013a).
This was indicated by lower macroscopic damage of the colon and less severe histopathological damage as compared to vehicletreated controls. In turn, this was associated with a decrease in various pro-inflammatory markers including MPO and cytokines IL-1 $\beta$, IL-6, and TNF- $\alpha$. The beneficial effects of targeting said receptor was also seen in a chronic model of DSS-induced colitis. Furthermore, we identified a role for $5-\mathrm{HT}_{7}$ receptor mediated cytokine release by mature DCs isolated from DSS-treated mice. Similar effects of 5-HT on cytokine secretion have been observed in monocyte-derived DCs (Müller et al., 2009). Importantly, it was recently reported that increased $5-\mathrm{HT}_{7}$ receptor-positive cells in DSS-treated mice were also positive for CD11c, suggesting that there is increased amount of $5-\mathrm{HT}_{7}$ receptor expressing DCs upon inflammation (Guseva et al., 2014).

By using chimeric mice that were reconstituted with bone marrow (BM) cells lacking $5-\mathrm{HT}_{7}$ receptor expression, we found that wild-type recipients that received $\mathrm{BM}$ cells from $5-\mathrm{HT}_{7}$ receptor deficient donors showed lower disease activity and less severe histopathological damage (Kim et al., 2013a). This suggests that $5-\mathrm{HT}_{7}$ receptor activation on immune cells play a key role in mediating intestinal inflammation in experimental colitis. Contrary to our data, Guseva et al. (2014) found that pharmacological blockade or genetic deletion of the $5-\mathrm{HT}_{7}$ receptor in DSSinduced colitis exacerbated colitis severity in mice. This may in large be due to the notable differences in experimental design and housing condition of animals. For instance, Guseva et al. (2014) administered the $5-\mathrm{HT}_{7}$ receptor antagonist at a lower dosage $(100 \mathrm{nM})$ for a shorter period of time, while we administered the antagonist throughout the duration of the DSS treatment at a much higher dosing range $(20-80 \mathrm{mg} / \mathrm{kg})$.

DCs are important players that orchestrate downstream immune responses from initial sampling of the luminal environment. As such, DCs play a crucial role in priming responses to Th1 and Th17 cells (important producers of IFN- $\gamma$ and IL-17, respectively). We reported alterations in colonic IFN- $\gamma$ and IL-17 levels in $5-\mathrm{HT}_{7}$ receptor antagonist-treated mice post DSS-induced colitis suggesting that there may be effects on T-cell responses when $5-\mathrm{HT}_{7}$ receptor signaling is disrupted in vivo (Kim et al., 2013a). Further investigation of the role of $5-\mathrm{HT}_{7}$ receptor signaling in T-cell function and examination of the role of DCs and sequential T cell activation in 
the context of gut inflammation will be necessary in order to elucidate the downstream effects of targeting this receptor in intestinal inflammation. In addition, the role of $5-\mathrm{HT}_{7}$ receptor activation in modulating other DC functions such as immune cell survival, remain to be determined. Recently, it has been reported that 5-HT stimulates human macrophage polarization through $5-\mathrm{HT}_{2 \mathrm{~B}}$ and $5-\mathrm{HT}_{7}$ receptors pointing to $5-\mathrm{HT}$ as a potential target for modulating macrophage polarization and the potential of targeting $5-\mathrm{HT}_{2 \mathrm{~B}}$ and $5-\mathrm{HT}_{7}$ receptors as therapies against inflammatory pathologies (de las Casas-Engel et al., 2013). Future studies investigating the role of these receptors on LP macrophages in the context of colitis would be interesting to determine the specific roles the $5-\mathrm{HT}_{7}$ receptor has on different cell types and subpopulations. Given the heterogeneity seen amongst immune cells in the intestine, it would not be surprising for $5-\mathrm{HT}_{7}$ receptor activation to play distinct roles in different cell types.

\section{ENTERIC INFECTIONS}

Alteration in the number of EC cells and 5-HT levels have been observed in enteric infection (Bearcroft et al., 1996; Spiller et al., 2000; Turvill et al., 2000; Kordasti et al., 2004; Wheatcroft et al., 2005). Recently, we examined the role of the $5-\mathrm{HT}_{7}$ receptor during enteric infection by using a murine model of large intestinal nematode infection, Trichuris muris. We found that expulsion of worms was significantly delayed in $5-\mathrm{HT}_{7}$ receptor deficient mice after $T$. muris infection and this was accompanied by an attenuation of infection-induced colonic muscle contractility. There was reduction in IL-9 levels in $5-\mathrm{HT}_{7}$ receptor deficient mice as compared to wild-type after infection (Kim et al., 2012). This suggests that the $5-\mathrm{HT}_{7}$ receptor plays an important role in generation of infection-induced intestinal muscle contractility, worm expulsion, and modulation of immune responses in the context of host defense in enteric infection.

\section{CONCLUSIONS AND FUTURE DIRECTIONS}

There is now abundant evidence in favor of an important role of 5-HT signaling in various gut disorders including IBD, IBS, and enteric infections. In the past two decades, there have been significant advances in our understanding of the $5-\mathrm{HT}_{7}$ receptor. Despite our best efforts, there are many unanswered questions and new avenues of research that still warrant investigation. Here, we highlighted the role of this receptor in the gut specifically in relation to inflammation and functional disorders; however, novel functions and roles for these receptors continue to emerge. Further elucidating the role of these receptors in intestinal function, and in intestinal pathologies and pathophysiology will help us to better understand the underlying mechanisms of various common intestinal disorders such as IBD and IBS, and will ultimately lead to the development of novel therapies. Further studies investigating $5-\mathrm{HT}_{7}$ receptor signaling in human samples from IBD patients and targeted inhibition of $5-\mathrm{HT}_{7}$ receptor function on mucosal DCs will be important in determining the role of the $5-\mathrm{HT}_{7}$ receptor in intestinal inflammation and to translate in vivo findings.

\section{ACKNOWLEDGMENTS}

The authors thank the Canadian Institutes for Health Research (CIHR) and Crohn's Colitis Canada (CCC). Waliul I. Khan is a recipient of a CIHR New Investigator Award.

\section{REFERENCES}

Ahonen, A., Kyösola, K., and Penttilä, O. (1976). Enterochromaffin cells in macrophages in ulcerative colitis and irritable colon. Ann. Clin. Res. 8, 1-7.

Andresen, V., and Camilleri, M. (2006). Irritable bowel syndrome: recent and novel therapeutic approaches. Drugs 66, 1073-1088. doi: 10.2165/00003495200666080-00004

Arnett, H. A., and Viney, J. L. (2010). Gatekeepers of intestinal inflammation. Inflamm. Res. 59, 1-14. doi: 10.1007/s00011-009-0091-x

Bard, J. A., Zgombick, J., Adham, N., Vaysse, P., Branchek, T. A., and Weinshank, R. L. (1993). Cloning of a novel human serotonin receptor (5-HT7) positively linked to adenylate cyclase. J. Biol. Chem. 268, 23422-23426.

Bearcroft, C. P., Perrett, D., and Farthing, M. J. (1996). 5-hydroxytryptamine release into human jejunum by cholera toxin. Gut 39, 528-531. doi: 10.1136/gut.39. 4.528

Beattie, D. T., and Smith, J. A. (2008). Serotonin pharmacology in the gastrointestinal tract: a review. Naunyn Schmiedebergs. Arch. Pharmacol. 377, 181-203. doi: 10.1007/s00210-008-0276-9

Belai, A., Boulos, P. B., Robson, T., and Burnstock, G. (1997). Neurochemical coding in the small intestine of patients with Crohn's disease. Gut 40, 767-774. doi: 10.1136/gut.40.6.767

Bercik, P., Park, A. J., Sinclair, D., Khoshdel, A., Lu, J., Huang, X., et al. (2011). The anxiolytic effect of Bifidobacterium longum NCC3001 involves vagal pathways for gut-brain communication. Neurogastroenterol. Motil. 23, 1132-1139. doi: 10. 1111/j.1365-2982.2011.01796.x

Bercik, P., Verdu, E. F., Foster, J. A., Macri, J., Potter, M., Huang, X., et al. (2010). Chronic gastrointestinal inflammation induces anxiety-like behavior and alters central nervous system biochemistry in mice. Gastroenterology 139, 2102-2112.e1. doi: 10.1053/j.gastro.2010.06.063

Berndt, B. E., Zhang, M., Chen, G. H., Huffnagle, G. B., and Kao, J. Y. (2007). The role of dendritic cells in the development of acute dextran sulfate sodium colitis. J. Immunol. 179, 6255-6262. doi: 10.4049/jimmunol.179.9.6255

Bernstein, C. N., and Shanahan, F. (2008). Disorders of a modern lifestyle: reconciling the epidemiology of inflammatory bowel diseases. Gut 57, 1185-1191. doi: 10.1136/gut.2007.122143

Bertrand, P. P., and Bertrand, R. L. (2010). Serotonin release and uptake in the gastrointestinal tract. Auton. Neurosci. 153, 47-57. doi: 10.1016/j.autneu.2009. 08.002

Bhalla, P., Saxena, P. R., and Sharma, H. S. (2002). Molecular cloning and tissue distribution of mRNA encoding porcine 5-HT7 receptor and its comparison with the structure of other species. Mol. Cell. Biochem. 238, 81-88. doi: 10. 1023/A:1019959121602

Bischoff, S. C., Mailer, R., Pabst, O., Weier, G., Sedlik, W., Li, Z., et al. (2009). Role of serotonin in intestinal inflammation: knockout of serotonin reuptake transporter exacerbates 2,4,6-trinitrobenzene sulfonic acid colitis in mice. Am. J. Physiol. Gastrointest. Liver Physiol. 296, G685-G695. doi: 10.1152/ajpgi.90685. 2008

Bishop, A. E., Pietroletti, R., Taat, C. W., Brummelkamp, W. H., and Polak, J. M. (1987). Increased populations of endocrine cells in Crohn's ileitis. Virchows Arch. A Pathol. Anat. Histopathol. 410, 391-396. doi: 10.1007/bf00712758

Bonaz, B. L., and Bernstein, C. N. (2013). Brain-gut interactions in inflammatory bowel disease. Gastroenterology 144, 36-49. doi: 10.1053/j.gastro.2012.10.003

Bouma, G., and Strober, W. (2003). The immunological and genetic basis of inflammatory bowel disease. Nat. Rev. Immunol. 3, 521-533. doi: 10.1038/nril132

Carter, D., Champney, M., Hwang, B., and Eglen, R. M. (1995). Characterization of a postjunctional 5-HT receptor mediating relaxation of guinea-pig isolated ileum. Eur. J. Pharmacol. 280, 243-250. doi: 10.1016/0014-2999(95) 00195-q

Chan, A. K., and von der Weid, P.-Y. (2003). 5-HT decreases contractile and electrical activities in lymphatic vessels of the guinea-pig mesentery: role of 5 HT 7-receptors. Br. J. Pharmacol. 139, 243-254. doi: 10.1038/sj.bjp.0705264

Chen, J. J., Li, Z., Pan, H., Murphy, D. L., Tamir, H., Koepsell, H., et al. (2001). Maintenance of serotonin in the intestinal mucosa and ganglia of mice that 
lack the high-affinity serotonin transporter: abnormal intestinal motility and the expression of cation transporters. J. Neurosci. 21, 6348-6361.

Coates, M. D., Mahoney, C. R., Linden, D. R., Sampson, J. E., Chen, J., Blaszyk, H., et al. (2004). Molecular defects in mucosal serotonin content and decreased serotonin reuptake transporter in ulcerative colitis and irritable bowel syndrome. Gastroenterology 126, 1657-1664. doi: 10.1053/j.gastro.2004. 03.013

Cole, J. A., Cook, S. F., Sands, B. E., Ajene, A. N., Miller, D. P., and Walker, A. M. (2004). Occurrence of colon ischemia in relation to irritable bowel syndrome. Am. J. Gastroenterol. 99, 486-491. doi: 10.1111/j.1572-0241.2004.04097.x

Collins, S. M., and Bercik, P. (2009). The relationship between intestinal microbiota and the central nervous system in normal gastrointestinal function and disease. Gastroenterology 136, 2003-2014. doi: 10.1053/j.gastro.2009.01.075

Collins, S. M., Surette, M., and Bercik, P. (2012). The interplay between the intestinal microbiota and the brain. Nat. Rev. Microbiol. 10, 735-742. doi: 10. 1038/nrmicro2876

Cryan, J. F., and O'Mahony, S. M. (2011). The microbiome-gut-brain axis: from bowel to behavior. Neurogastroenterol. Motil. 23, 187-192. doi: 10.1111/j.13652982.2010.01664.x

de las Casas-Engel, M., Domínguez-Soto, A., Sierra-Filardi, E., Bragado, R., Nieto, C., Puig-Kroger, A., et al. (2013). Serotonin skews human macrophage polarization through HTR2B and HTR7. J. Immunol. 190, 2301-2310. doi: 10. 4049/jimmunol.1201133

Dickson, E. J., Heredia, D. J., and Smith, T. K. (2010). Critical role of 5-HT1A, 5HT3 and 5-HT7 receptor subtypes in the initiation, generation and propagation of the murine colonic migrating motor complex. Am. J. Physiol. Gastrointest. Liver Physiol. 299, G144-G157. doi: 10.1152/ajpgi.00496.2009

El Aidy, S., Kunze, W., Bienenstock, J., and Kleerebezem, M. (2012). The microbiota and the gut-brain axis: insights from the temporal and spatial mucosal alterations during colonisation of the germfree mouse intestine. Benef. Microbes 3, 251-259. doi: 10.3920/BM2012.0042

El-Salhy, M., Danielsson, A., Stenling, R., and Grimelius, L. (1997). Colonic endocrine cells in inflammatory bowel disease. J. Intern. Med. 242, 413-419. doi: 10.1046/j.1365-2796.1997.00237.x

Fedorak, R. N., Wong, K., and Bridges, R. (2010). Canadian digestive health foundation public impact series. Inflammatory bowel disease in Canada: incidence, prevalence and direct and indirect economic impact. Can. J. Gastroenterol. 24, 651-655.

Forsythe, P., and Kunze, W. A. (2013). Voices from within: gut microbes and the CNS. Cell. Mol. Life Sci. 70, 55-69. doi: 10.1007/s00018-012-1028-z

Gershon, M. D., and Tack, J. (2007). The serotonin signaling system: from basic understanding to drug development for functional GI disorders. Gastroenterology 132, 397-414. doi: 10.1053/j.gastro.2006.11.002

Ghia, J. E., Li, N., Wang, H., Collins, M., Deng, Y., El-Sharkawy, R. T., et al. (2009). Serotonin has a key role in pathogenesis of experimental colitis. Gastroenterology 137, 1649-1660. doi: 10.1053/j.gastro.2009.08.041

Goodhand, J. R., Greig, F. I. S., Koodun, Y., McDermott, A., Wahed, M., Langmead, L., et al. (2012). Do antidepressants influence the disease course in inflammatory bowel disease? A retrospective case-matched observational study. Inflamm. Bowel Dis. 18, 1232-1239. doi: 10.1002/ibd.21846

Graff, L. A., Walker, J. R., and Bernstein, C. N. (2009). Depression and anxiety in inflammatory bowel disease: a review of comorbidity and management. Inflamm. Bowel Dis. 15, 1105-1118. doi: 10.1002/ibd.20873

Gunawardene, A. R., Corfe, B. M., and Staton, C. A. (2011). Classification and functions of enteroendocrine cells of the lower gastrointestinal tract. Int. J. Exp. Pathol. 92, 219-231. doi: 10.1111/j.1365-2613.2011.00767.x

Guseva, D., Holst, K., Kaune, B., Meier, M., Keubler, L., Glage, S., et al. (2014). Serotonin 5-HT7 receptor is critically involved in acute and chronic inflammation of the gastrointestinal tract. Inflamm. Bowel Dis. 20, 1516-1529. doi: 10.1097/MIB. 0000000000000150

Ham, T. S. (2002). Regional distribution and relative frequency of gastrointestinal endocrine cells in large intestines of C57BL/6 mice. J. Vet. Sci. 3, 233-238.

Haub, S., Ritze, Y., Bergheim, I., Pabst, O., Gershon, M. D., and Bischoff, S. C. (2010). Enhancement of intestinal inflammation in mice lacking interleukin 10 by deletion of the serotonin reuptake transporter. Neurogastroenterol. Motil. 22, 826-834, e229. doi: 10.1111/j.1365-2982.2010.01479.x

Hedlund, P. B. (2009). The 5-HT7 receptor and disorders of the nervous system: an overview. Psychopharmacology (Berl) 206, 345-354. doi: 10.1007/s00213-009$1626-0$
Hedlund, P. B., Danielson, P. E., Thomas, E. A., Slanina, K., Carson, M. J., and Sutcliffe, J. G. (2003). No hypothermic response to serotonin in 5-HT7 receptor knockout mice. Proc. Natl. Acad. Sci. U S A 100, 1375-1380. doi: 10.1073/pnas. 0337340100

Hoyer, D., Hannon, J. P., and Martin, G. R. (2002). Molecular, pharmacological and functional diversity of 5-HT receptors. Pharmacol. Biochem. Behav. 71, 533-554. doi: 10.1016/s0091-3057(01)00746-8

Iceta, R., Mesonero, J. E., Aramayona, J. J., and Alcalde, A. I. (2009). Expression of 5-HT1A and 5-HT7 receptors in Caco-2 cells and their role in the regulation of serotonin transporter activity. J. Physiol. Pharmacol. 60, 157-164.

Idzko, M., Panther, E., Stratz, C., Müller, T., Bayer, H., Zissel, G., et al. (2004). The serotoninergic receptors of human dendritic cells: identification and coupling to cytokine release. J. Immunol. 172, 6011-6019. doi: 10.4049/jimmunol.172.10. 6011

Irving, H. R., Tan, Y. Y., Tochon-Danguy, N., Liu, H., Chetty, N., Desmond, P. V., et al. (2007). Comparison of 5-HT4 and 5-HT7 receptor expression and function in the circular muscle of the human colon. Life Sci. 80, 1198-1205. doi: 10.1016/j.lfs.2006.12.025

Janssen, P., Prins, N. H., Meulemans, A. L., and Lefebvre, R. A. (2002). Pharmacological characterization of the 5-HT receptors mediating contraction and relaxation of canine isolated proximal stomach smooth muscle. Br. J. Pharmacol. 136, 321-329. doi: 10.1038/sj.bjp.0704716

Khan, W. I., Motomura, Y., Wang, H., El-Sharkawy, R. T., Verdu, E. F., VermaGandhu, M., et al. (2006). Critical role of MCP-1 in the pathogenesis of experimental colitis in the context of immune and enterochromaffin cells. Am. J. Physiol. Gastrointest. Liver Physiol. 291, G803-G811. doi: 10.1152/ajpgi.00069. 2006

Kim, J. J., Bridle, B. W., Ghia, J.-E., Wang, H., Syed, S. N., Manocha, M. M., et al. (2013a). Targeted inhibition of serotonin type 7 (5-HT7) receptor function modulates immune responses and reduces the severity of intestinal inflammation. J. Immunol. 190, 4795-4804. doi: 10.4049/jimmunol.1201887

Kim, J. J., Wang, H., Terc, J. D., Sunjic, I., Zambrowicz, B., Yang, Q. M., et al. (2013b). Sa2017 blocking peripheral serotonin synthesis by telotristat etiprate reduces the severity of both chemical- and infection-induced intestinal inflammation. Gastroenterology 144, S-360. doi: 10.1016/S0016-5085(13)61326-8

Kim, J. J., Wang, H., Zaman, T., Hedlund, P. B., Ghia, J.-E., and Khan, W. I. (2012). Role of 5-HT7 in intestinal muscle function and host defense in an enteric parastic infection. Neurogastroenterol. Motil. 24, 43-190. doi: 10.1111/j.13652982.2012.01997.x

Koloski, N. A., Bret, L., and Radford-Smith, G. (2008). Hygiene hypothesis in inflammatory bowel disease: a critical review of the literature. World J. Gastroenterol. 14, 165-173. doi: 10.3748/wjg.14.165

Kordasti, S., Sjövall, H., Lundgren, O., and Svensson, L. (2004). Serotonin and vasoactive intestinal peptide antagonists attenuate rotavirus diarrhoea. Gut 53 , 952-957. doi: 10.1136/gut.2003.033563

Krishnan, V., and Nestler, E. J. (2008). The molecular neurobiology of depression. Nature 455, 894-902. doi: 10.1038/nature07455

Ku, S. K., Lee, H. S., and Lee, J. H. (2006). The regional distribution and relative frequency of gastrointestinal endocrine cells in the nude mice, Balb/c-nu/nu: an immunohistochemical study. Anat. Histol. Embryol. 35, 104-110. doi: 10.1111/j. 1439-0264.2005.00645.x

Ladabaum, U. (2003). Safety, efficacy and costs of pharmacotherapy for functional gastrointestinal disorders: the case of alosetron and its implications. Aliment. Pharmacol. Ther. 17, 1021-1030. doi: 10.1046/j.1365-2036.2003.01545.x

Larsson, K., Lööf, L., Rönnblom, A., and Nordin, K. (2008). Quality of life for patients with exacerbation in inflammatory bowel disease and how they cope with disease activity. J. Psychosom. Res. 64, 139-148. doi: 10.1016/j.jpsychores. 2007.10.007

Levenstein, S. (2002). Psychosocial factors in peptic ulcer and inflammatory bowel disease. J. Consult. Clin. Psychol. 70, 739-750. doi: 10.1037//0022-006x.70.3.739

Li, N., Ghia, J. E., Wang, H., McClemens, J., Cote, F., Suehiro, Y., et al. (2011). Serotonin activates dendritic cell function in the context of gut inflammation. Am. J. Pathol. 178, 662-671. doi: 10.1016/j.ajpath.2010.10.028

Linden, D. R., Foley, K. F., McQuoid, C., Simpson, J., Sharkey, K. A., and Mawe, G. M. (2005). Serotonin transporter function and expression are reduced in mice with TNBS-induced colitis. Neurogastroenterol. Motil. 17, 565-574. doi: 10. $1111 / j .1365-2982.2005 .00673 . x$

Lipscomb, M. F., and Masten, B. J. (2002). Dendritic cells: immune regulators in health and disease. Physiol. Rev. 82, 97-130. doi: 10.1152/physrev.00023.2001 
Loftus, E. V. Jr. (2004). Clinical epidemiology of inflammatory bowel disease: incidence, prevalence and environmental influences. Gastroenterology 126, 15041517. doi: 10.1053 /j.gastro.2004.01.063

Lovenberg, T. W., Baron, B. M., de Lecea, L., Miller, J. D., Prosser, R. A., Rea, M. A., et al. (1993). A novel adenylyl cyclase-activating serotonin receptor (5-HT7) implicated in the regulation of mammalian circadian rhythms. Neuron 11, 449458. doi: 10.1016/0896-6273(93)90149-1

Lyte, M., Varcoe, J. J., and Bailey, M. T. (1998). Anxiogenic effect of subclinical bacterial infection in mice in the absence of overt immune activation. Physiol. Behav. 65, 63-68. doi: 10.1016/s0031-9384(98)00145-0

Magro, F., Vieira-Coelho, M. A., Fraga, S., Serrão, M. P., Veloso, F. T., Ribeiro, T., et al. (2002). Impaired synthesis or cellular storage of norepinephrine, dopamine and 5-hydroxytryptamine in human inflammatory bowel disease. Dig. Dis. Sci. 47, 216-224. doi: 10.1023/A:1013256629600

Mardini, H. E., Kip, K. E., and Wilson, J. W. (2004). Crohn's disease: a twoyear prospective study of the association between psychological distress and disease activity. Dig. Dis. Sci. 49, 492-497. doi: 10.1023/b:ddas.0000020509.23 $162 . c c$

Margolis, K. G., Stevanovic, K., Li, Z., Yang, Q. M., Oravecz, T., Zambrowicz, B., et al. (2013). Pharmacological reduction of mucosal but not neuronal serotonin opposes inflammation in mouse intestine. Gut 63, 928-937. doi: 10.1136/gutjnl2013-304901

Martel, F., Monteiro, R., and Lemos, C. (2003). Uptake of serotonin at the apical and basolateral membranes of human intestinal epithelial (Caco-2) cells occurs through the neuronal serotonin transporter (SERT). J. Pharmacol. Exp. Ther. 306, 355-362. doi: 10.1124/jpet.103.049668

Mawe, G. M., and Hoffman, J. M. (2013). Serotonin signalling in the gut-functions, dysfunctions and therapeutic targets. Nat. Rev. Gastroenterol. Hepatol. 10, 473486. doi: 10.1038/nrgastro.2013.105

Meuser, T., Pietruck, C., Gabriel, A., Xie, G.-X., Lim, K.-J., and Pierce Palmer, P. (2002). 5-HT7 receptors are involved in mediating 5-HT-induced activation of rat primary afferent neurons. Life Sci. 71, 2279-2289. doi: 10.1016/s00243205(02)02011-8

Meyerhof, W., Obermüller, F., Fehr, S., and Richter, D. (1993). A novel rat serotonin receptor: primary structure, pharmacology and expression pattern in distinct brain regions. DNA Cell Biol. 12, 401-409. doi: 10.1089/dna.1993. 12.401

Mikocka-Walus, A. A., Turnbull, D. A., Moulding, N. T., Wilson, I. G., Andrews, J. M., and Holtmann, G. J. (2006). Antidepressants and inflammatory bowel disease: a systematic review. Clin. Pract. Epidemiol. Ment. Health 2:24. doi: 10. 1186/1745-0179-2-24

Mittermaier, C., Dejaco, C., Waldhoer, T., Oefferlbauer-Ernst, A., Miehsler, W., Beier, M., et al. (2004). Impact of depressive mood on relapse in patients with inflammatory bowel disease: a prospective 18-month follow-up study. Psychosom. Med. 66, 79-84. doi: 10.1097/01.psy.0000106907.24881.f2

Mnie-Filali, O., Lambas-Señas, L., Scarna, H., and Haddjeri, N. (2009). Therapeutic potential of 5-HT7 receptors in mood disorders. Curr. Drug Targets 10, 11091117. doi: $10.2174 / 138945009789735129$

Mössner, R., and Lesch, K.-P. (1998). Role of serotonin in the immune system and in neuroimmune interactions. Brain Behav. Immun. 12, 249-271. doi: 10. 1006/brbi.1998.0532

Motomura, Y., Ghia, J. E., Wang, H., Akiho, H., El-Sharkawy, R. T., Collins, M., et al. (2008). Enterochromaffin cell and 5-hydroxytryptamine responses to the same infectious agent differ in Th1 and Th2 dominant environments. Gut 57, 475-481. doi: 10.1136/gut.2007.129296

Mowat, A. M., and Bain, C. C. (2011). Mucosal macrophages in intestinal homeostasis and inflammation. J. Innate Immun. 3, 550-564. doi: 10.1159/0003 29099

Müller, T., Dürk, T., Blumenthal, B., Grimm, M., Cicko, S., Panther, E., et al. (2009). 5-hydroxytryptamine modulates migration, cytokine and chemokine release and T-cell priming capacity of dendritic cells in vitro and in vivo. PLoS One 4:e6453. doi: 10.1371/journal.pone.0006453

Nilsson, O., Ahlman, H., Geffard, M., Dahlström, A., and Ericson, L. E. (1987). Bipolarity of duodenal enterochromaffin cells in the rat. Cell Tissue Res. 248, 49-54. doi: 10.1007/bf01239961

O’Hara, J. R., Skinn, A. C., MacNaughton, W. K., Sherman, P. M., and Sharkey, K. A. (2006). Consequences of Citrobacter rodentium infection on enteroendocrine cells and the enteric nervous system in the mouse colon. Cell. Microbiol. 8, 646660. doi: $10.1111 /$ j.1462-5822.2005.00657.x
O’Mahony, S. M., Clarke, G., Borre, Y. E., Dinan, T. G., and Cryan, J. F. (2014). Serotonin, tryptophan metabolism and the brain-gut- microbiome axis. Behav. Brain Res. doi: 10.1016/j.bbr.2014.07.027. [Epub ahead of print]

Oshima, S., Fujimura, M., and Fukimiya, M. (1999). Changes in number of serotonin-containing cells and serotonin levels in the intestinal mucosa of rats with colitis induced by dextran sodium sulfate. Histochem. Cell Biol. 112, 257263. doi: $10.1007 / \mathrm{s} 004180050445$

Persoons, P., Vermeire, S., Demyttenaere, K., Fischler, B., Vandenberghe, J., Van Oudenhove, L., et al. (2005). The impact of major depressive disorder on the short- and long-term outcome of Crohn's disease treatment with infliximab. Aliment. Pharmacol. Ther. 22, 101-110. doi: 10.1111/j.1365-2036.2005. 02535.x

Plassat, J. L., Amlaiky, N., and Hen, R. (1993). Molecular cloning of a mammalian serotonin receptor that activates adenylate cyclase. Mol. Pharmacol. 44, 229-236.

Porcelli, P., Leoci, C., and Guerra, V. (1996). A prospective study of the relationship between disease activity and psychologic distress in patients with inflammatory bowel disease. Scand. J. Gastroenterol. 31, 792-796. doi: 10. 3109/00365529609010354

Prins, N. H., Briejer, M. R., Van Bergen, P. J., Akkermans, L. M., and Schuurkes, J. A. (1999). Evidence for 5-HT7 receptors mediating relaxation of human colonic circular smooth muscle. Br. J. Pharmacol. 128, 849-852. doi: 10.1038/sj.bjp. 0702762

Racké, K., Reimann, A., Schwörer, H., and Kilbinger, H. (1996). Regulation of 5HT release from enterochromaffin cells. Behav. Brain Res. 73, 83-87. doi: 10. 1016/0166-4328(96)00075-7

Rehfeld, J. F. (1998). The new biology of gastrointestinal hormones. Physiol. Rev. 78, 1087-1108.

Rindi, G., Leiter, A. B., Kopin, A. S., Bordi, C., and Solcia, E. (2004). The "normal" endocrine cell of the gut: changing concepts and new evidences. Ann. N Y Acad. Sci. 1014, 1-12. doi: 10.1196/annals.1294.001

Roberts, A. J., and Hedlund, P. B. (2012). The 5-HT(7) receptor in learning and memory. Hippocampus 22, 762-771. doi: 10.1002/hipo.20938

Ruat, M., Traiffort, E., Leurs, R., Tardivel-Lacombe, J., Diaz, J., Arrang, J. M., et al. (1993). Molecular cloning, characterization and localization of a high-affinity serotonin receptor (5-HT7) activating cAMP formation. Proc. Natl. Acad. Sci. U S A 90, 8547-8551. doi: 10.1073/pnas.90.18.8547

Ruhé, H. G., Mason, N. S., and Schene, A. H. (2007). Mood is indirectly related to serotonin, norepinephrine and dopamine levels in humans: a meta-analysis of monoamine depletion studies. Mol. Psychiatry 12, 331-359. doi: 10.1038/sj.mp. 4001949

Savelieva, K. V., Zhao, S., Pogorelov, V. M., Rajan, I., Yang, Q., Cullinan, E., et al. (2008). Genetic disruption of both tryptophan hydroxylase genes dramatically reduces serotonin and affects behavior in models sensitive to antidepressants. PLoS One 3:e3301. doi: 10.1371/journal.pone.0003301

Schäfermeyer, A., Gratzl, M., Rad, R., Dossumbekova, A., Sachs, G., and Prinz, C. (2004). Isolation and receptor profiling of ileal enterochromaffin cells. Acta Physiol. Scand. 182, 53-62. doi: 10.1111/j.1365-201x.2004.01299.x

Shajib, M. S., Wang, H., Kim, J. J., Sunjic, I., Ghia, J.-E., Denou, E., et al. (2013). Interleukin 13 and serotonin: linking the immune and endocrine systems in murine models of intestinal inflammation. PLoS One 8:e72774. doi: 10. 1371/journal.pone.0072774

Sharkey, K. A., and Mawe, G. M. (2002). Neuroimmune and epithelial interactions in intestinal inflammation. Curr. Opin. Pharmacol. 2, 669-677. doi: 10. 1016/s1471-4892(02)00215-1

Shen, Y., Monsma, F. J., Metcalf, M. A., Jose, P. A., Hamblin, M. W., Sibley, D. R., et al. (1993). Molecular cloning and expression of a 5-hydroxytryptamine7 serotonin receptor subtype. J. Biol. Chem. 268, 18200-18204.

Spiller, R. C., Jenkins, D., Thornley, J. P., Hebden, J. M., Wright, T., Skinner, M., et al. (2000). Increased rectal mucosal enteroendocrine cells, T lymphocytes and increased gut permeability following acute Campylobacter enteritis and in postdysenteric irritable bowel syndrome. Gut 47, 804-811. doi: 10.1136/gut.47.6.804

Tonini, M., Vicini, R., Cervio, E., De Ponti, F., De Giorgio, R., Barbara, G., et al. (2005). 5-HT7 receptors modulate peristalsis and accommodation in the guinea pig ileum. Gastroenterology 129, 1557-1566. doi: 10.1053/j.gastro.2005. 08.005

Trivedi, M. H., Rush, A. J., Wisniewski, S. R., Nierenberg, A. A., Warden, D., Ritz, L., et al. (2006). Evaluation of outcomes with citalopram for depression using measurement-based care in $\mathrm{STAR}^{\star} \mathrm{D}$ : implications for clinical practice. Am. J. Psychiatry 163, 28-40. doi: 10.1176/appi.ajp.163.1.28 
Tsou, A. P., Kosaka, A., Bach, C., Zuppan, P., Yee, C., Tom, L., et al. (1994). Cloning and expression of a 5-hydroxytryptamine7 receptor positively coupled to adenylyl cyclase. J. Neurochem. 63, 456-464. doi: 10.1046/j.1471-4159.1994. 63020456.x

Tuladhar, B. R., Ge, L., and Naylor, R. J. (2003). 5-HT7 receptors mediate the inhibitory effect of 5-HT on peristalsis in the isolated guinea-pig ileum. Br. J. Pharmacol. 138, 1210-1214. doi: 10.1038/sj.bjp.0705184

Turvill, J. L., Connor, P., and Farthing, M. J. (2000). The inhibition of cholera toxin-induced 5-HT release by the 5-HT(3) receptor antagonist, granisetron, in the rat. Br. J. Pharmacol. 130, 1031-1036. doi: 10.1038/sj.bjp.07 03414

Vanhoenacker, P., Haegeman, G., and Leysen, J. E. (2000). 5-HT7 receptors: current knowledge and future prospects. Trends Pharmacol. Sci. 21, 70-77. doi: 10. 1016/s0165-6147(99)01432-7

Walker, J. R., Ediger, J. P., Graff, L. A., Greenfeld, J. M., Clara, I., Lix, L., et al. (2008). The Manitoba IBD cohort study: a population-based study of the prevalence of lifetime and 12-month anxiety and mood disorders. Am. J. Gastroenterol. 103, 1989-1997. doi: 10.1111/j.1572-0241.2008.01980.x

Walker, E. A., Gelfand, M. D., Gelfand, A. N., Creed, F., and Katon, W. J. (1996). The relationship of current psychiatric disorder to functional disability and distress in patients with inflammatory bowel disease. Gen. Hosp. Psychiatry 18, 220-229. doi: 10.1016/0163-8343(96)00036-9

Walther, D. J., and Bader, M. (2003). A unique central tryptophan hydroxylase isoform. Biochem. Pharmacol. 66, 1673-1680. doi: 10.1016/s0006-2952(03) 00556-2

Walther, D. J., Peter, J. U., Bashammakh, S., Hörtnagl, H., Voits, M., Fink, H., et al. (2003). Synthesis of serotonin by a second tryptophan hydroxylase isoform. Science 299:76. doi: 10.1126/science.1078197

Wang, H., Steeds, J., Motomura, Y., Deng, Y., Verma-Gandhu, M., El-Sharkawy, R. T., et al. (2007). CD4+ T cell-mediated immunological control of enterochromaffin cell hyperplasia and 5-hydroxytryptamine production in enteric infection. Gut 56, 949-957. doi: 10.1136/gut.2006.103226
Wheatcroft, J., Wakelin, D., Smith, A., Mahoney, C. R., Mawe, G., and Spiller, R. (2005). Enterochromaffin cell hyperplasia and decreased serotonin transporter in a mouse model of postinfectious bowel dysfunction. Neurogastroenterol. Motil. 17, 863-870. doi: 10.1111/j.1365-2982.2005.00719.x

Whitehead, W. E., Palsson, O., and Jones, K. R. (2002). Systematic review of the comorbidity of irritable bowel syndrome with other disorders: what are the causes and implications? Gastroenterology 122, 1140-1156. doi: 10.1053/gast. 2002.32392

Yang, G. B., and Lackner, A. A. (2004). Proximity between 5-HT secreting enteroendocrine cells and lymphocytes in the gut mucosa of rhesus macaques (Macaca mulatta) is suggestive of a role for enterochromaffin cell 5-HT in mucosal immunity. J. Neuroimmunol. 146, 46-49. doi: 10.1016/j.jneuroim.2003. 10.044

Zou, B. C., Dong, L., Wang, Y., Wang, S. H., and Cao, M. B. (2007). Expression and role of 5-HT7 receptor in brain and intestine in rats with irritable bowel syndrome. Chin. Med. J. (Engl) 120, 2069-2074.

Conflict of Interest Statement: The authors declare that the research was conducted in the absence of any commercial or financial relationships that could be construed as a potential conflict of interest.

Received: 20 July 2014; accepted: 27 October 2014; published online: 11 December 2014.

Citation: Kim JJ and Khan WI (2014) 5-HT 7 receptor signaling: improved therapeutic strategy in gut disorders. Front. Behav. Neurosci. 8:396. doi: 10.3389/fnbeh.2014.00396 This article was submitted to the journal Frontiers in Behavioral Neuroscience.

Copyright (C) $2014 \mathrm{Kim}$ and Khan. This is an open-access article distributed under the terms of the Creative Commons Attribution License (CC BY). The use, distribution and reproduction in other forums is permitted, provided the original author(s) or licensor are credited and that the original publication in this journal is cited, in accordance with accepted academic practice. No use, distribution or reproduction is permitted which does not comply with these terms. 